\title{
Novel role for the transient receptor potential channel TRPM2 in prostate cancer cell proliferation
}

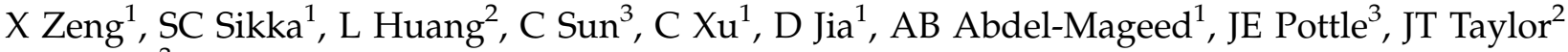 \\ and $\mathrm{M} \mathrm{Li}^{3}$ \\ ${ }^{1}$ Department of Urology, Tulane University Health Sciences Center, New Orleans, LA, USA; ${ }^{2}$ Department of Pharmacology, Tulane \\ University Health Sciences Center, New Orleans, LA, USA and ${ }^{3}$ Department of Physiology, Tulane University Health Sciences \\ Center, New Orleans, LA, USA
}

\begin{abstract}
We have identified a novel function for a member of the transient receptor potential (TRP) protein super-family, TRPM2, in prostate cancer cell proliferation. TRPM2 encodes a non-selective cationpermeable ion channel. We found that selectively knocking down TRPM2 with the small interfering RNA technique inhibited the growth of prostate cancer cells but not of non-cancerous cells. The subcellular localization of this protein is also remarkably different between cancerous and non-cancerous cells. In BPH-1 (benign), TRPM2 protein is homogenously located near the plasma membrane and in the cytoplasm, whereas in the cancerous cells (PC-3 and DU-145), a significant amount of the TRPM2 protein is located in the nuclei in a clustered pattern. Furthermore, we have found that TRPM2 inhibited nuclear ADP-ribosylation in prostate cancer cells. However, TRPM2 knockdown-induced inhibition of proliferation is independent of the activity of poly(ADP-ribose) polymerases. We conclude that TRPM2 is essential for prostate cancer cell proliferation and may be a potential target for the selective treatment of prostate cancer.

Prostate Cancer and Prostatic Diseases (2010) 13, 195-201; doi:10.1038/pcan.2009.55; published online 22 December 2009
\end{abstract}

Keywords: TRPM2; siRNA; PARP; proliferation

\section{Introduction}

Prostate cancer is the second most prevalent cancer among men over 50 years of age, with nearly 30000 men dying from the disease each year in the United States. Although many theories have been proposed and investigated, the exact mechanism leading to development and progression of prostate cancer remains unknown. However, recent reports suggest that transient receptor potential (TRPs) ion channel super-families have a significant role in regulating calcium homeostasis during prostate carcinogenesis. ${ }^{1}$ The function of TRPM2 in cancer cells has recently been investigated. ${ }^{2,3}$ Using a cDNA array technique, significantly increased TRPM2 mRNA expression has been observed in prostate cancer tissues and cell lines in comparison with normal prostate tissues (http://www.ncbi.nlm.nih.gov/projects/geo/gds).

TRPM2 is a member of the TRP protein super-family of ion channels ${ }^{4,5}$ that can be activated by ADP-ribose, ${ }^{6}$ $\beta$-NAD, ${ }^{7} \mathrm{TNF}^{8},{ }^{8}$ or $\mathrm{H}_{2} \mathrm{O}_{2},{ }^{9}$ which results in an increase in intracellular free calcium concentration $\left(\left[\mathrm{Ca}^{2+}\right]_{\mathrm{i}}\right){ }^{10}$

Correspondence: Dr M Li, Department of Physiology, Tulane University Health Sciences Center, SL-39, 1430 Tulane Avenue, New Orleans, LA 70112, USA.

E-mail: mli@tulane.edu

Received 29 May 2009; revised 10 September 2009; accepted 5 October 2009; published online 22 December 2009
ADP-ribose is a breakdown product of $\mathrm{NAD}^{+}, \mathrm{CD} 38$, cADP-ribose, and protein de-acetylation. ${ }^{411}$ As a bifunctional protein, TRPM2 protein contains a Nudix box in its C-terminus, ${ }^{12}$ which is a common motif of enzymes that degrade nucleotide diphosphates in addition to serving as a binding site for ADP-ribose. ${ }^{13}$ This study is designed to closely evaluate the role of TRPM2 in cell proliferation of prostate cancer cells.

\section{Materials and methods}

Prostate cancer tissue sections

Small blocks of fresh prostate cancer tissue were obtained during radial prostatectomy of prostate cancer patients (mean age of 61 and Gleason score range of 6-8) at Tulane Hospital and Clinics and the VA Hospital in New Orleans, LA, USA (consent was approved by institution review board for such studies). Tissues were snap-frozen in liquid nitrogen after being carefully embedded in Tissue-Tek OCT Compound (Jed Pella Inc., Redding, CA, USA). Samples were microtomed into $6-7 \mu \mathrm{m}$ thick sections, mounted onto clean uncoated glass slides, and stored at $-80^{\circ} \mathrm{C}$ until further processing.

Laser capture microdissection and RNA preparation The sections were thawed at room temperature for $10 \mathrm{~s}$, followed by normal hemotoxylin and eosin staining, air 
dried, and subjected to laser capture microdissection (LCM) using a PixCell II instrument and CapSure LCM Caps (Arcturus Engineering, Mountain View, CA, USA). Matched tumor cells and benign prostate epithelium from LCM procured prostate from the same patient were captured separately after identification, confirmation, staging, and grading of the tissue area by a certified pathologist. Laser captured cells from multiple serial sections (roughly 2000-3000 pulses at spot diameter of $30 \mu \mathrm{m}$ and $25-35 \mathrm{~mW}$ laser power) were pooled into a $500 \mu \mathrm{l}$ nuclease-free Eppendorf tube containing $400 \mu \mathrm{l}$ of TRI Reagent (Molecular Research Centre Inc., Cincinnati, $\mathrm{OH}, \mathrm{USA})$ mixed with RNA carrier, $1 \mu \mathrm{l}$ of $10 \mu \mathrm{g} \mathrm{l}^{-1}$ of GenEluteTM Linear PolyAcrylamide (Sigma, St Louis, MO, USA). After recovery of the RNA pellet, a DNase treatment step was performed for $2 \mathrm{~h}$ at $37^{\circ} \mathrm{C}$ using 2 unit of RQ1 RNase-free Dnase (Promega Corp., Madison, WI, USA), followed by re-extraction and precipitation. The RNA yield and integrity was determined using Agilent 2100 bioanalyzer (Agilent Technologies, Palo Alto, CA, USA) with RNA LabChip (Ambion Inc., Austin, TX, USA). Only RNA samples with distinguished bands of $28 \mathrm{~S}$ and $18 \mathrm{~S}$ and without multiple RNA degradation bands were subjected to further analysis.

\section{Cell culture}

The human prostate epithelial cell line BPH-1 was a gift from Dr Stuart W Hayward and Dr R Dahia of the University of San Francisco. Other prostate cell lines, including RWPE-1, PC-3, DU-145, and LNCaP were purchased from ATCC (Manassas, VA, USA). For comparison purposes, human cavernosal smooth muscle cells routinely grown as primary culture in our laboratory and maintained in DMEM media containing $10 \%$ heat inactivated fetal bovine serum were used as controls for these studies. BPH-1, PC-3, DU-145, and LNCaP cells were grown in RPMI-1640 medium containing 5\% fetal bovine serum. Normal epithelial RWPE-1 cells were grown in kerationcyte-SFM medium containing $5 \mathrm{ng} \mathrm{ml}^{-1}$ epidermal growth factor and $50 \mu \mathrm{g} \mathrm{ml}^{-1}$ bovine pituitary extract (Invitrogen Corp., Carlsbad, CA, USA). All cells were cultured in a humidified incubator with $5 \% \mathrm{CO}_{2}$ and $95 \%$ air at $37^{\circ} \mathrm{C}$.

\section{Cell proliferation analysis}

Proliferation was assessed using a WST-8 assay according to manufacturer's instructions. Briefly, $10 \mu \mathrm{l}$ of 2-(2-methoxy-4-nitrophenyl)-3-(4-nitrophenyl)-5-(2,4-disulphonyl)-2H-etrazolium (WST-8) was added to each well at the end of treatment and incubated for one additional hour. Optical density values were read by an ELISA plate reader at wavelengths of 450 and $650 \mathrm{~nm}$. Results were calculated as percentage of control. For the PARP activity experiment, PC-3 cells were seeded in a 96-well plate at a density of approximately $10^{3}$ cells per well, in triplicate. The following day, the cells were treated with the PARP inhibitor NU1025 at concentrations ranging from 0.2 to $2 \mathrm{mM}$ for 24 and $72 \mathrm{~h}$.

Quantitative real-time PCR and RT-PCR

For quantitative real-time PCR, the primers of TRPM2 were forward: 5'-CCATCCGTGACCTTCTCATT-3' and reverse: 5'-CTCTGAGCCCAGATGATTCC-3' (reverse). The primers of $\beta$-actin used for real-time PCR were forward: 5'-GGCACCCAGCACAATGAAG-3' and reverse: 5'-GCCGATCCACACGGAGTACT 3' (reverse). SYBR Green PCR master mix (Applied Biosystems, Warrington, UK) was used to develop the real-time PCR in a thermal cycler (GeneAmp 5700, Applied Biosystems). A validation experiment was carried out to check whether the efficiencies of all target and reference primers were approximately equal.

For RT-PCR, RNA was extracted from prostate epithelial cell lines and cancer cell lines using TRI-REAGENT (Molecular Research Center Inc.). A $2 \mu \mathrm{g}$ sample of total RNA from each cell line was incubated with 1 unit of RNase-free DNase for $10 \mathrm{~min}$ at $37^{\circ} \mathrm{C}$ and then at $65^{\circ} \mathrm{C}$ for another $10 \mathrm{~min}$. Random primers $(1 \mu \mathrm{g})$ were then added and the tube was kept at $70{ }^{\circ} \mathrm{C}$ for $5 \mathrm{~min}$. Subsequently, $5 \mu \mathrm{l}$ of Moloney murine leukemia virus reverse transcriptase reaction buffer $(5 \times), 1 \mu \mathrm{l}$ of $10 \mathrm{mM}$ PCR nucleotide mix, 25 units of rRNasin ribonuclease inhibitor, and 200 units of Moloney murine leukemia virus reverse transcriptase were added to the tube and incubated at $37^{\circ} \mathrm{C}$ for $1 \mathrm{~h}$. All reagents were purchased from Promega Co. The cDNA product $(2 \mu \mathrm{l})$ was mixed with 1.5 units TaKaRa Taq, $2.5 \mu \mathrm{l} 10 \times$ PCR buffer, $2 \mu \mathrm{l} 2.5 \mathrm{mM}$ dNTP mixture (TaKaRa Shuzo Co., Otsu, Japan), and $100 \mathrm{pM}$ of each primer, with DEPC water added for a final volume of $25 \mu \mathrm{l}$. The primers for TRPM2 were forward: $5^{\prime}$-ATGCTA CCTCGGAAGCTGAA-3' ${ }^{\prime}$ and reverse: 5'-TTCTGGAGGA GGGTCTTGTG-3'; for TRPC3-forward: 5'-CAAGTACC CTCCAACCCTCA-3' and reverse: $5^{\prime}$-CTGGCTGCTAG ATCCCAGAA-3'; for TRPV5-forward: 5'-CGCTGTTGT GAACCAGAATG-3' and reverse: 5'-GCTGGAGGATG AGgatgtgt-3'; for GAPDH-forward: 5'-TCAACGGATTT GGTCGTATTGGG-3' and reverse: 5'-TGATTTTGGAGG GATCTCGC-3'. The amplification protocol for PCR was set as follows: $94{ }^{\circ} \mathrm{C}$ for $4 \mathrm{~min}$, followed by 30 cycles of amplification steps $\left(94^{\circ} \mathrm{C}\right.$ for $2 \mathrm{~min}, 60^{\circ} \mathrm{C}$ for $30 \mathrm{~s}, 72^{\circ} \mathrm{C}$ for $40 \mathrm{~s}$ ), and the final extension at $72^{\circ} \mathrm{C}$ for $8 \mathrm{~min}$. PCR products were analyzed using agarose gel (1.5\%) electrophoresis and visualized under UV light after staining with ethidium bromide $\left(1 \mu \mathrm{g} \mathrm{ml}^{-1}\right)$.

\section{Western blot analysis}

For nuclear protein extraction, nuclei were isolated from both prostate cancer cell lines (PC-3 and DU-145) and non-cancerous cell lines (BPH and RWPE-1) using CelLytic NucLEAR Extraction kit (Sigma-Aldrich Inc.). The nuclei were lysed and extracted by centrifugation at $13000 \mathrm{~g}$ for $5 \mathrm{~min}$. The supernatant was collected and protein concentrations were determined using BCA reagent (PIERCE Chemical Co., Rockford, IL, USA). For western blot analysis, an equal amount of protein $(50 \mu \mathrm{g})$ from each cell extract was separated in SDS-PAGE gels (Bio-Rad Laboratories, Hercules, CA, USA). The proteins were transferred electrophoretically to a $0.2 \mu \mathrm{m}$ nitrocellulose membrane. Non-fat dry milk (5\%) in PBS containing $0.1 \%$ Tween 20 (PBS-T) was used as a blocking agent for $1 \mathrm{~h}$ at room temperature. The membrane was then treated with 1:300 dilution of TRPM2 primary antibody (Bethyl Laboratories Inc., Montgomery, TX, USA) at $4{ }^{\circ} \mathrm{C}$ overnight, rinsed briefly with PBS-T twice, and incubated with HRP-conjugated secondary antibody (dilution 1:2000 in PBS-T) for $1 \mathrm{~h}$ at room temperature 
with constant agitation. The film was developed with the ECL western blot detection reagent kit (Amersham Pharmacia Biotech, Piscataway, NJ, USA).

\section{Immunofluorescent confocal microscopy}

Cells were placed on chamber slides for 1 day to allow for attachment. Cells were then subsequently washed three times with PBS, fixed with methanol at $-20^{\circ} \mathrm{C}$ for $10 \mathrm{~min}$, and permeabilized in $0.5 \%$ Triton X-100 in PBS for $5 \mathrm{~min}$. After treatment with $20 \%$ goat serum for $10 \mathrm{~min}$, cells were incubated with primary antibody (rabbit anti-TRPM2, 1:50, Bethyl Laboratories Inc.) for $60 \mathrm{~min}$ at room temperature, which was followed by secondary antibody (goat antirabbit IgG FITC conjugated, 1:200, Bethyl Laboratories Inc.) for $30 \mathrm{~min}$ in darkness. Propidium iodide (Abcam Inc., Cambridge, MA, USA) was used for nuclear staining. Confocal microscopy was performed using a Leica TCS SP2 confocal microscope equipped with five lasers, including Argon $488 \mathrm{~nm}$ and HeNe $543 \mathrm{~nm}$ (Leica Microsystems, Exton, PA, USA).

\section{Small interfering RNA assay}

Cells were cultured on 96-well microplates until $\sim 30 \%$ confluence and then transfected with $40 \mathrm{nM}$ of either small interfering RNA (siRNA) specific to TRPM2 (5'-AUAGAUCAGGAACUCCGUCUC-3') or scrambled siRNA (Integrated DNA Technology, Coralville, IA, USA) using Lipofectamine 2000 transfection reagent (Invitrogen) according to the manufacturer's instructions. Cell growth was monitored by a WST-8 cell counting kit (Alexis Biochemicals Corp., San Diego, CA, USA).

\section{Statistical analysis}

All data are expressed as mean \pm standard deviation. For statistical analysis, Student's $t$-test was used to compare the differences between control and treatment groups. A probability value of $P<0.05$ is considered statistically significant and denoted by asterisk marks in the figures.

\section{Results}

TRPM2 mRNA expression in cancerous vs benign tissue The expression of TRPM2 mRNA was examined using real-time PCR in cells isolated by laser capture microdissection from tumor tissues isolated from prostate cancer patients as compared with that from cells of the benign tissues of the same subjects. Our qRT-PCR analysis demonstrated selective high expression of TRPM2 transcripts in 75\% of LCM-procured malignant cells in comparison to matched microdissected benign cells of surgical specimens (Table 1). It is noteworthy that TRPM2 expression does not correlate with age or Gleason score. However, our results further emphasize the need to confirm these observations in a large cohort of prostate cancer patients.

TRPM2 mRNA expression in prostate cancer cell lines RT-PCR analysis was performed to evaluate TRPM2 mRNA expression in prostate cancer cell lines (DU-145, LNCaP, and PC-3). As shown in Figure 1, all three types of cells yielded a clear PCR product band (293 bp) of
TRPM2 in prostate cancer cell proliferation $\mathrm{X}$ Zeng et al

Table 1 Quantitative real-time RT-PCR test of the abundance of TRPM2 in prostate cancer tissues from patients

\begin{tabular}{lccc}
\hline $\begin{array}{l}\text { Patient's } \\
\text { code }\end{array}$ & $\begin{array}{c}\text { Age when } \\
\text { surgery }\end{array}$ & $\begin{array}{c}\text { Gleason } \\
\text { score }\end{array}$ & $\begin{array}{c}\text { TRPM2 level } \\
\text { (cancer/BPE) }\end{array}$ \\
\hline$\# 18$ & 59 & 6 & 5.31 \\
$\# 24$ & 58 & 6 & 17.63 \\
$\# 34$ & 70 & 8 & 10.93 \\
$\# 39$ & 54 & 6 & 3.53 \\
$\# 56$ & 68 & 7 & 1.13 \\
$\# 65$ & 64 & 6 & 4.08 \\
$\# 71$ & 65 & 6 & 0.91 \\
$\# 82$ & 53 & 7 & 0.62 \\
\hline
\end{tabular}

Abbreviation: $\mathrm{BPH}$, benign prostate epithelium.

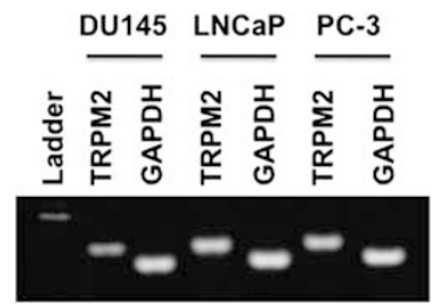

Figure 1 RT-PCR analysis of TRPM2 mRNA expression in prostate cancer cell lines. BPH, benign prostatic hyperplasia.

TRPM2. These data suggest that these cell lines are appropriate models for studying the mechanism of TRPM2 underlying cancer progression.

Subcellular expression of TRPM2 in prostate cells We examined the sub-cellular distribution of TRPM2 in prostate cancer and non-cancerous prostate cell lines using immunofluorescent confocal microscopy. As shown in Figure 2a, TRPM2 proteins are located at the plasma membrane and cytoplasm in BPH-1 cells. However, in the prostate cancer cell lines (PC-3 and DU-145), TRPM2 is also highly expressed in the nuclear region in a clustered pattern. The expression of TRPM2 in RWPE-1 cells is very low in our experiment. To confirm the predominant expression of TRPM2 in the nuclei of prostate cancer cells, nuclear proteins from PC-3 and DU-145 cells were extracted and analyzed using western blot analysis. Equal amounts of protein extracts $(50 \mu \mathrm{g})$ from the different cell lines were used for western blot analysis. As shown in Figure 2b, expression of TRPM2 protein was detected in the nuclei of prostate cancer cells (PC-3 and DU-145). In contrast, TRPM2 was absent in the nuclei of benign (BPH-1) or normal prostate epithelium cells (RWPE-1). These data confirm that TRPM2 is expressed in the nuclei of prostate cancer cells. Our western blot analysis also detected TRPM2 expression in the cytoplasm preparations in PC-3, DU-145, and BPH-1 cells, but not in RWPE-1 cells. This is consistent with the data in Figure 2a.

Involvement of TRPM2 in prostate cancer cell proliferation To examine the role of TRPM2 in prostate cancer cell proliferation, we conducted experiments to selectively block the expression of TRPM2 mRNA by transfecting 

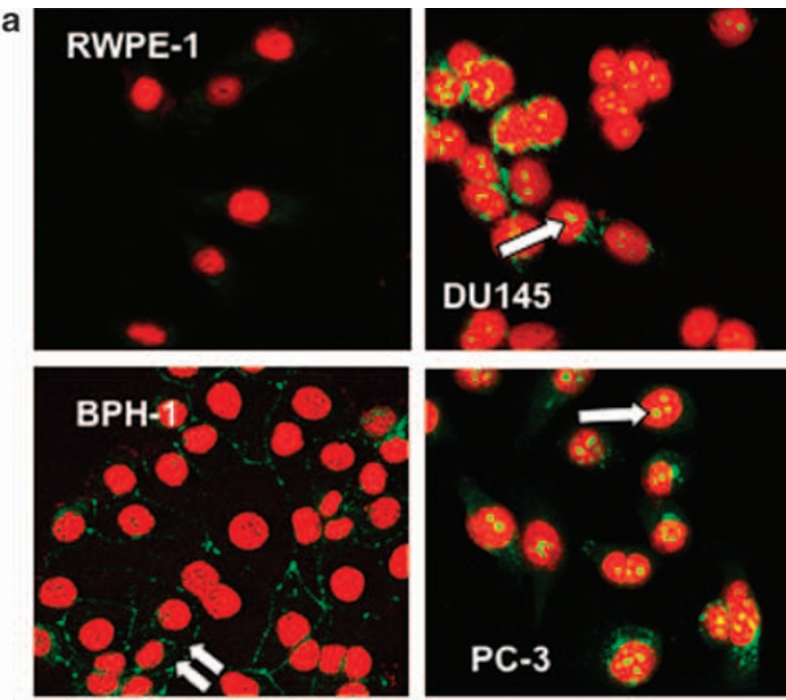

b

Nuclei

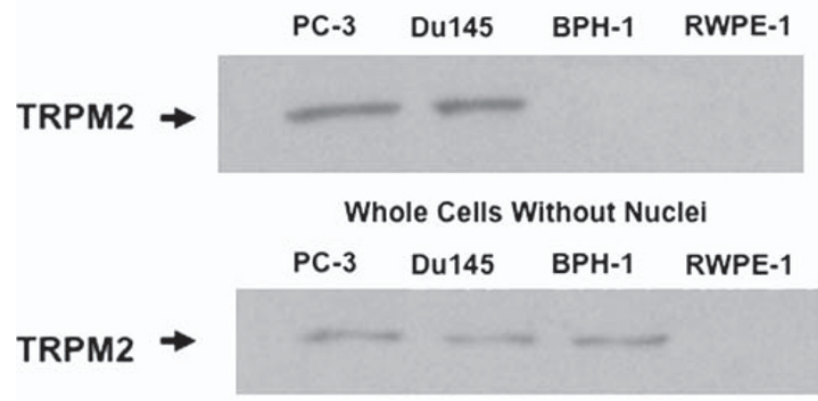

b-actin

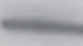

Figure 2 (a) Confocal microscopy showing the subcellular expression of TPRM2 protein in prostate cancer cell Lines (PC-3, DU-145), benign cells (BPH-1), and normal prostate epithelial cell line (RWPE-1). DU-145 is the 15th section of the z-series images (30 series). PC-3, BPH-1, and RWPE-1 are the 10th section of the z-series images (30 series). Red is propidium iodide (PI) label of nuclei and green is FITC fluorescence conjugated secondary antibody against TRPM2 antibody. Single arrows indicate the nuclear location of TRPM2 in cancer cells. Double arrow indicates plasma membrane expression of TRPM2 in BPH-1 cells. All images are the overlays of FITC and PI fluorescence. (b) Expression of TPRM2 proteins in both the nuclei and the remainders (whole cell preparation excluding nuclei) of prostate cancer cell lines (PC-3 and DU-145) and noncancerous prostate epithelium cell lines (BPH and RWPE-1).

siRNA specifically targeting TRPM2 (siRNA-TRPM2) into prostate cancer cells and non-cancerous prostate cells and examining the effect of the siRNA on the proliferation of these cells. As shown in Figure 3a, a significant inhibitory effect on prostate cancer cell proliferation was observed in siRNA-TRPM2-treated cells as compared with control cells that were not transfected with siRNA or cells treated with scrambled siRNA $(P<0.05)$. In contrast, siRNA-TRPM2 had no inhibitory effect on RWPE-1 or BPH-1 cell proliferation. These data suggest that knockdown of TRPM2 does not inhibit cell growth in non-cancerous prostate epithelial cells, but specifically inhibits growth of prostate cancer cells.

The efficiency of the siRNA-TRPM2 in suppressing TRPM2 expression was examined with the RT-PCR method. Figure $3 b$ shows that siRNA-TRPM2 successfully blocked the expression of TRPM2 mRNA in both PC-3 and DU-145 cells. The expression of TRPM2 protein was also inhibited by siRNA-TRPM2 treatment, as shown in Figure 3c. Western blot analysis shows the expression of TRPM2 protein was significantly reduced in PC-3 cells treated with siRNA-TRPM2 when compared with scrambled siRNA treatments. Pretreating the primary antibody with a specific blocking peptide completely prevented binding of the antibody to the TRPM2 protein.

\section{Effect of knockdown of TRPM2 on ADP-ribosylation in prostate cancer cells}

On the basis of the finding that TRPM2 is relocated in the nucleus of prostate cancer cells and the fact that TRPM2 has ADP-ribose pyrophosphatase activity, ${ }^{6,12}$ we hypothesized that TRPM2 may decrease the level of poly ADP-ribose in the nucleus of cancer cells by catalyzing ADP-ribose to ribose 5-phosphate and AMP. ${ }^{14}$ To test this hypothesis, we transfected (Lipofectamine, Invitrogen) siRNA-TRPM2 (40 nM) into PC-3 and BPH-1 cells for $72 \mathrm{~h}$ to knock down the expression of TRPM2 specifically. We then measured level of ADP-ribosylation in the cells with fluorescent microscopy and ELISA.

As shown in Figure 4a, control PC-3 cells and PC-3 cells treated with scrambled siRNA presented low levels of ADP-ribosylation, as indicated by only a few cells being stained with the red fluorescent dye (anti-ADPribose conjugated with Texas Red). Conversely, substantial increases in the occurrence and intensity of red fluorescence in stained PC-3 cells were observed in siRNA-TRPM2-treated cells, suggesting that an increase in ADP-ribosylation occurred even though the total number of living cells was reduced significantly under this condition. In Figure $4 a$, total cell number was less after the treatment with SiRNA-TRPM2 than the control or scrambled siRNA; this is consistent with the experimental result shown in Figure 3a.

An ELISA assay was used to evaluate the level of ADP-ribosylation in PC-3 and BPH-1 cells (Figure 4b). In general, the ADP-ribosylation was higher in PC-3 cells than that in BPH-1 cells. After treatment with siRNATRPM2 for $72 \mathrm{~h}$, an approximately threefold increase in the ADP-ribosylation was measured in PC-3 cells, whereas no observable difference was seen in BPH-1 cells. These data are consistent with our previous observation that showed specific TRPM2 protein expression in the nuclei of prostate cancer cells and no such expression in the nuclei of $\mathrm{BPH}-1$ cells.

\section{PARP-independent inhibition of ADP-ribosylation by TRPM2 in prostate cancer cells}

Poly ADP-ribosylation is a transient posttranslational modification of nuclear proteins, mainly catalyzed by poly ADP-ribose polymerases (PARPs). ADP-ribose in the nucleus is converted into poly ADP-ribose by PARPs, a process that has an important function in DNA repair ${ }^{15}$ and cell replication. ${ }^{16}$ Poly ADP-ribosylation also has a role in G0-G1 transition during cell cycle progression. ${ }^{17}$ Over-activation of PARP can cause cell necrosis because of the depletion of cytoplasmic ATP. ${ }^{18,19}$ To examine the 

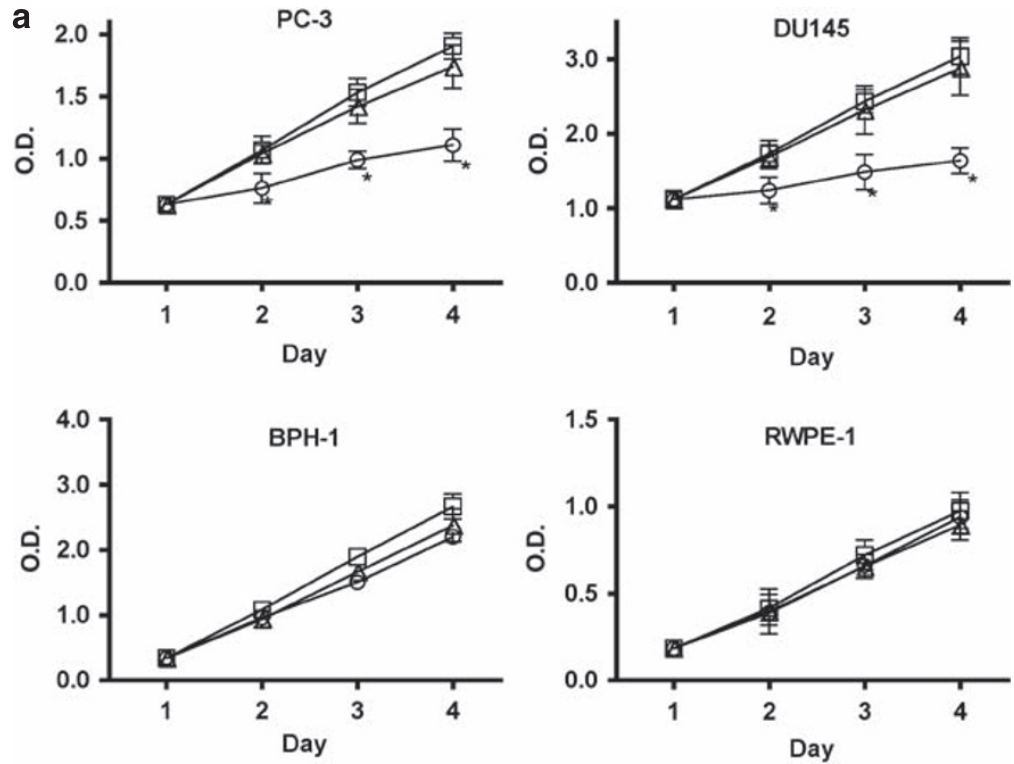
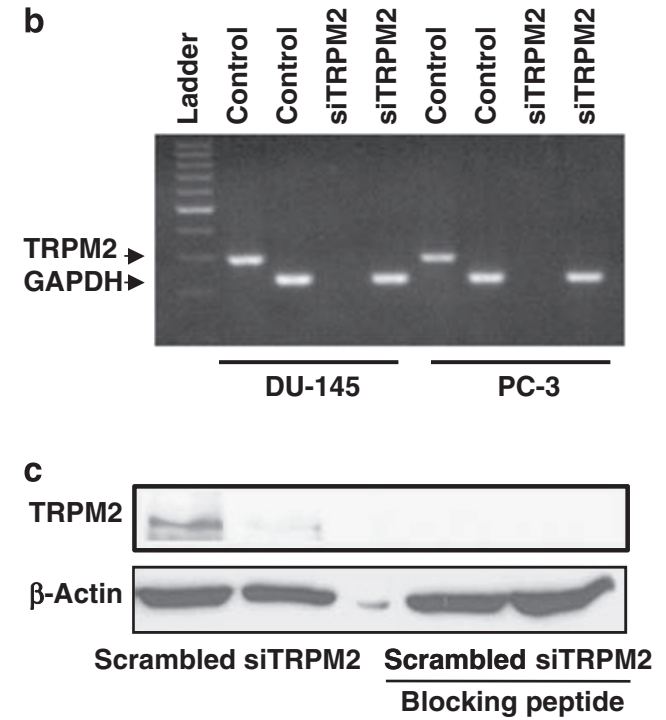

Figure 3 Selective inhibitory effect of siRNA-TRPM2 on prostate cancer cell proliferation. (a) Cell proliferation monitored in cell lines PC-3, DU-145, BPH-1, and RWPE-1 with WST-8 assay. The open square represents the data from untreated cells (control). The open triangle represents data from cells treated with $40 \mathrm{nM}$ scrambled siRNA. The open circle represents the data from cells treated with $40 \mathrm{nM}$ siRNATRPM2. $N=3$ for all groups. Error bar represents the standard deviation. *Indicates $P<0.05$ between siRNA-TRPM2 treatment and the two other groups. (b) RT-PCR showed that TRPM2 mRNA expression is inhibited by the siRNA-TRPM2 treatment in DU-145 and PC-3 2 days after the siRNA transfection. The sizes of PCR products are $293 \mathrm{bp}$ and $234 \mathrm{bp}$ for TRPM2 and GAPDH, respectively. (c) Western blot shows that TRPM2 protein expression is inhibited in PC-3 by $40 \mathrm{nM}$ siRNA-TRPM2 treatment for $72 \mathrm{~h}$. Repeated three times. siTRPM2: siRNATRPM2.

potential role of PARPs in TRPM2-mediated proliferation of prostate cancer cells, we used the PARP-1 inhibitor NU1025 (8-hydroxy-2-methylquinazoline-4(3H)one) to inhibit the activity of the major subtype of PARPs, PARP-1, ${ }^{20}$ in cells treated with siRNA-TRPM2. Dose-dependent toxicity of NU1025 on PC-3 cell proliferation starts at $200 \mu \mathrm{M}$ (Figure 4c). PC-3 cells were seeded in a 96-well plate at $\sim 1000$ cells per well in triplicate. Then, cells were treated with $100 \mu \mathrm{M}$ of NU1025 together with siRNA-TRPM2 or scrambled siRNA for 4 days. NU1025 treatment did not affect cell proliferation when it was applied alone; NU1025 cotreatment did not rescue TRPM2-siRNA-mediated inhibition of cell proliferation (Figure $4 \mathrm{~d}$ ). These results suggest that TRPM2 knockdown-induced inhibition of proliferation is independent of the activity of poly (ADP-ribose) polymerases.

\section{Discussion}

Previous studies have shown that TRPM2 channels are expressed primarily in the plasma membrane and have a key role in oxidative stress-induced cell death. ${ }^{12}$ Our results show a unique and previously unreported role for the TRPM2 protein, facilitating or promoting cell proliferation in cancer cells. The observation of a $\mathrm{Ca}^{2+}$ channel plays a non- $\mathrm{Ca}^{2+}$ transport function is surprising, but not completely new. It has been reported that an L-type voltage-gated $\mathrm{Ca}^{2+}$ channel is proteolytically cleaved to form a C-terminal fragment, which is translocated into the nucleus and alters the endogenous transcription of a wide variety of genes. ${ }^{21}$ However, the molecular mechanisms that mediate this change in functionality in the TRPM2 protein between cancerous and non-cancerous tissues remain elusive. The difference in the subcellular locations of TRPM2 between cancerous and non-cancerous prostate cells may explain the switching of these two roles. In non-cancerous cells, TRPM2 proteins are mainly located at the plasma membrane where they mediate sodium and calcium influx on oxidative stimulation. As a result, these cation influxes may lead to membrane depolarization and changes in calcium homeostasis that can lead to programed cell death. In cancer cells, the role of TRPM2 as a plasma membrane ion channel is less important because of the internalization and nuclear localization of TRPM2. Abundant TRPM2 proteins are translocated into the nucleus (Figure 2) where they may have an important enzymatic function relating to cancer cell proliferation. We anticipate this TRPM2 nuclear translocation is a more general phenomenon as we also have observed it in other types of cancer cells (data not shown).

It has been reported that two fragments (sense and antisense transcriptions) of TRPM2 are specifically expressed in cancer cells, ${ }^{3}$ as our PCR and antibody targeted the C-terminus (exons 30-32, exon 25, respectively) it will be very interesting to see if the nuclear expressed TRPM2 represent or include the TRPM2 fragment of the sense transcription. If so, the cancerspecific transcription will create two functionally important fragment proteins-the antisense fragments inhibit the normal $\mathrm{Ca}^{2+}$ transport function of TRPM2 and the sense fragment conducts enzymatic function in the nucleus simultaneously.

Zhang et al. ${ }^{22}$ have suggested that TRPM2 activation resulted in PARP cleavage and inactivation in hematopoietic cells through a mechanism involving $\left[\mathrm{Ca}^{2+}\right]_{\mathrm{i}}$ elevation. Our data show that knocking down TRPM2 increased 

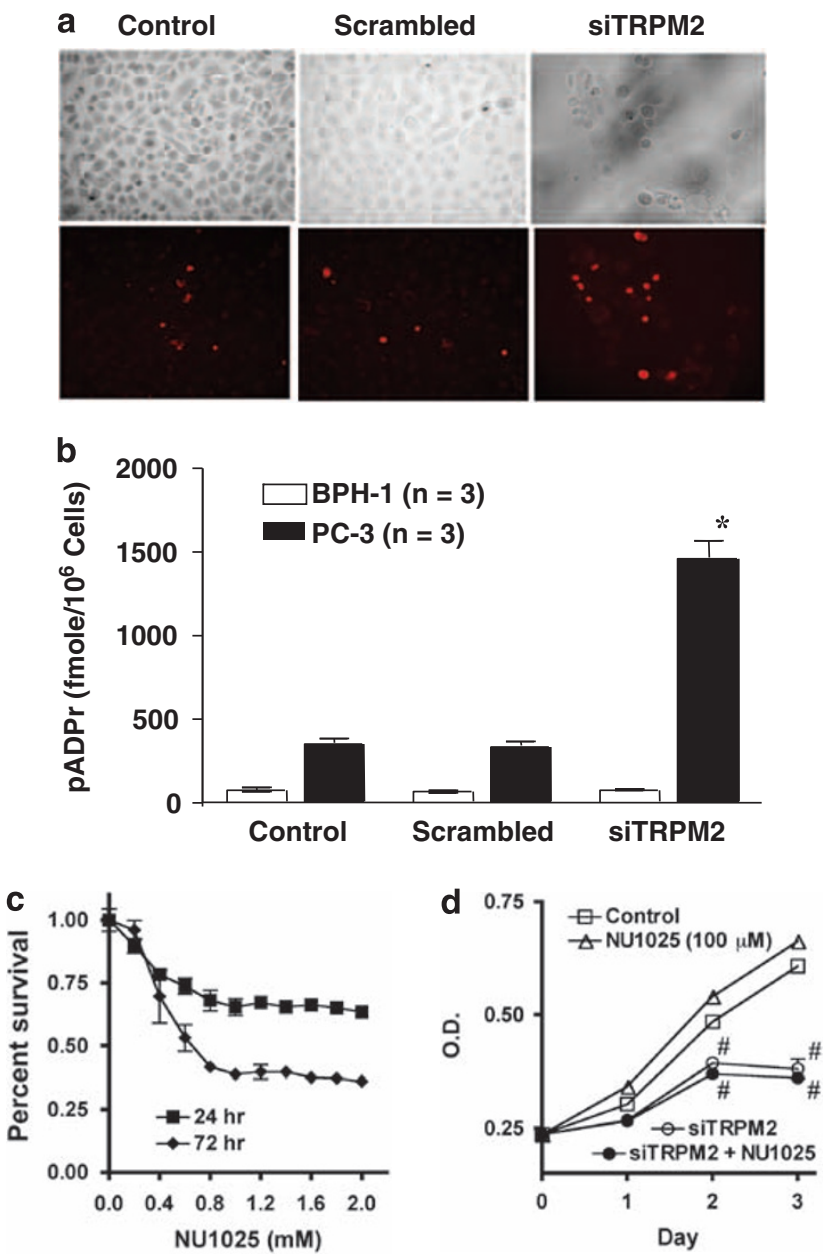

Figure 4 Effect of siRNA-TRPM2 on ADP-ribosylation in PC-3 cells. (a) Immunofluorescence indicating ADP-ribosylation in PC-3 cells transfected with no siRNA (control), scrambled siRNA, or siRNA-TRPM2. The magnification for all of the images is $\times 10$. (b) ELISA measurement of ADP-ribosylation in PC-3 and BPH-1 cells. *Indicates $P<0.01$ of Student's $t$-test between the siRNA-TRPM2 treated and the control groups. (c) Dose-dependent toxic effect of UN1025 on PC-3 cells. (d) PC-3 cell proliferation of under the conditions of $40 \mathrm{nM}$ siRNA-TRPM2 treatment and co-treatment with siRNA-TRPM2 and $100 \mu \mathrm{M}$ UN1025. "Indicates $P<0.05$ of Student's $t$-test between the siRNA-TRPM2 or UN1025+siRNA-TRPM2 treated and the control groups.

PARP activity in prostate cancer cells through a unresolved mechanism and also that direct blockade of PARP-1 activity by NU1025 did not prevent siRNA-TRPM2-induced inhibition of prostate cancer cell proliferation (Figure $4 \mathrm{~d}$ ). These data suggest the activity of PARP-1 may not have a crucial role in siRNA-TRPM2-induced inhibition of cancer cell growth. Therefore, TRPM2 may have an important function in cell proliferation independent of the activity of PARPs in prostate cancer cells.

Dual localization in the plasma membrane and endoplasmic reticulum has been observed for TRPM8 ion channel in prostate cancer cells. TRPM8 is closely related to TRPM2, with $42 \%$ homology. ${ }^{23}$ TRPM8 is highly expressed in endoplasmic reticulum membrane as an ion channel in prostate cancer cells and has an essential role in prostate cancer cell survival. ${ }^{24,25}$ However, nuclear expression of this channel has not been seen in prostate cancer cells as we have observed for TRPM2. Whether TRPM2 also functions as an endoplasmic reticulum calcium channel in prostate cancer cells is currently unknown. Our data strongly suggest that TRPM2 has a major function in the nuclei of prostate cancer cells.

Intracellular $\left[\mathrm{Ca}^{2+}\right]$ regulation has a crucial role in tumorigenesis, including cell replication and apoptosis. ${ }^{26}$ Nuclear expression of TRPM2 may also influence nuclear $\mathrm{Ca}^{2+}$ concentration $\left[\mathrm{Ca}^{2+}\right]_{n}$. The nuclear envelope comprises an inner membrane that abuts the nucleoplasm and an outer membrane that is continuous with the endoplasmic reticulum. Anchored within this envelope are the nuclear pore complexes and several intracellular calcium store-regulating molecules that have been reported to have a role in the regulation of $\left[\mathrm{Ca}^{2+}\right]_{\mathrm{n}}$. For example, inositol 1,4,5-trisphosphate $\left(\mathrm{IP}_{3}\right)$ and inositol 1,3,4,5-tetrakisphosphate $\left(\mathrm{IP}_{4}\right)$ binding sites have been identified in the inner membrane of the nuclear envelope. ${ }^{27-29} \mathrm{IP}_{3}$ and $\mathrm{IP}_{4}$ serve as signal molecules for either $\mathrm{Ca}^{2+}$ release $\left(\mathrm{IP}_{3}\right)$ or sequestration $\left(\mathrm{IP}_{4}\right)$ in the nucleus. ${ }^{30}$ Another example is, cADP-ribose, an endogenous regulator of type 2 ryanodine receptors that induces $\mathrm{Ca}^{2+}$ release from nuclear stores. ${ }^{31}$ More detailed information concerning the nuclear location of TRPM2 will be useful in advancing our knowledge of this aspect of prostate cancer proliferation.

The mechanism of TRPM2 transmigration into the nucleus is currently unknown. TRPM2 itself does not contain a nuclear localization signaling sequence; therefore, a chaperone may be involved in TRPM2 transportation. A similar mechanism could also be present for TRPM2 considering evidence that inositol 1,4,5-trisphosphate receptors $\left(\mathrm{IP}_{3} \mathrm{R}\right)$ can migrate into the nucleus and $\mathrm{IP}_{3} \mathrm{R}$ directly binds to TRPC channels. ${ }^{32,33}$

TRPM2 is expressed in many non-cancerous cells, such as brain and peripheral blood cells. ${ }^{7,8,34}$ Considering the function of TRPM2 in these cells is to serve as a mediator of oxidative-stress-induced calcium influx (i.e., the channel is at plasma membrane) and thus apoptosis in those tissues, inhibition of TRPM2 may be beneficial in terms of continued survival. ${ }^{35}$ Selectively suppressing the expression of TRPM2 or blocking the transmigration of these proteins into the nucleus may not harm noncancerous cells, but may selectively inhibit prostate cancer growth. Therefore, TRPM2 may be a potential target for the selective control of prostate cancer growth and cell proliferation.

\section{Conflict of interest}

The authors declare no conflict of interest.

\section{Acknowledgements}

We thank Dr B Miller (Pennsylvania State University) for constructive comments. Supported by ADA research award (ML) and DOD PA031119 (ABA).

\section{References}

1 Pervarskaya N, Flourakis M, Bidaux G, Thebault S, Skryma R. Differential role of TRP channels in prostate cancer. Biochem Soc Trans 2007; 35: 133-135. 
2 Ishii M, Oyama A, Hagiwara T, Miyazaki A, Mori Y, Kiuchi Y et al. Facilitation of $\mathrm{H}_{2} \mathrm{O}_{2}$-induced A172 human glioblastoma cell death by insertion of oxidative stress-sensitive TRPM2 channels. Anticancer Res 2007; 27: 3987-3992.

3 Orfanelli U, Wenke A-K, Doglioni C, Russo V, Bosserhoff AK, Lavorgna G. Identification of novel sense and antisense transcription at the TRPM2 locus in cancer. Cell Res 2008; 18: 1128-1140.

4 Clapham DE. TRP channels as cellular sensors. Nature 2003; 426: 517-524.

5 Perraud AL, Schmitz C, Scharenberg AM. TRPM2 $\mathrm{Ca}^{2+}$ permeable cation channels: from gene to biological function. Cell Calcium 2003; 33: 519-531.

6 Perraud AL, Fleig A, Dunn CA, Bagley LA, Launay P, Schmitz C et al. ADP-ribose gating of the calcium-permeable LTRPC2 channel revealed by Nudix motif homology. Nature 2001; 411: 595-599.

7 Sano Y, Inamura K, Miyake A, Mochizuki S, Yokoi H, Matsushime $\mathrm{H}$ et al. Immunocyte $\mathrm{Ca}^{2+}$ influx system mediated by LTRPC2. Science 2001; 293: 1327-1330.

8 Hara Y, Wakamori M, Ishii M, Maeno E, Nishida M, Yoshida T et al. LTRPC2 $\mathrm{Ca}^{2+}$-permeable channel activated by changes in redox status confers susceptibility to cell death. Mol Cell 2002; 9: 163-173.

9 Wehage E, Eisfeld J, Heiner I, Jungling E, Zitt C, Luckhoff A. Activation of the cation channel long transient receptor potential channel 2 (LTRPC2) by hydrogen peroxide. A splice variant reveals a mode of activation independent of ADP-ribose. J Biol Chem 2002; 277: 23150-23156.

10 Kraft R, Grimm C, Grosse K, Hoffmann A, Sauerbruch S, Kettenmann $\mathrm{H}$ et al. Hydrogen peroxide and ADP-ribose induce TRPM2-mediated calcium influx and cation currents in microglia. Am J Physiol 2004; 286: C129-C137.

11 Rafty LA, Schmidt MT, Perraud AL, Scharenberg AM, Denu JM. Analysis of O-acetyl-ribose as a target for Nudix ADP-ribose hydrolases. J Biol Chem 2002; 277: 47114-47122.

12 Zhang W, Chu X, Tong Q, Cheung JY, Conrad K, Masker K et al. A novel TRPM2 isoform inhibits calcium influx and susceptibility to cell death. J Biol Chem 2003; 278: 16222-16229.

13 Bessman MJ, Frick DN, O'Handley SF. The MutT proteins or 'Nudix' hydrolases, a family of versatile, widely distributed, 'housecleaning' enzymes. J Biol Chem 1996; 271: 25059-25062.

14 Naziroglu M. New molecular mechanism on the activation of TRPM2 channels by oxidative stress and ADP-ribose. Neurochem Res 2007; 32: 1990-2001.

15 Shell S, de Murcia G. Poly(ADP-ribose) polymerase-1: what have we learned from the deficient mouse model? Mutat Res 2000; 460: 1-15.

16 Virag L, Szabo C. The therapeutic potential of poly(ADP-ribose) polymerase inhibitors. Pharmacol Rev 2002; 54: 375-429.

17 Carbone M, Rossi MN, Cavaldesi M, Notari A, Amati P, Maione R. Poly(ADP-ribosyl)ation is implicated in the G0-G1 transition of resting cells. Oncogene 2008; 27: 6083-6092.

18 Schreiber V, Hunting D, Trucco C, Gowans B, Grunwald D, de Murcia $G$ et al. A dominant negative mutant of human poly(ADP-ribose) polymerase affect cell recovery, apoptosis and sister chromatid exchange following DNA damage. Proc Natl Acad Sci USA 1995; 92: 4753-4757.

19 Kleczkowska HE, Althaus FR. The role of poly(ADP-ribosyl)lation in the adaptive response. Mutat Res 1996; 35: 215-221.
20 Bowman KJ, White A, Golding BT, Griffin RJ, Curtin NJ. Potentiation of anti-cancer agent cytotoxicity by the potent poly(ADP-ribose) polymerase inhibitors NU1025 and NU1064. Br J Cancer 1998; 78: 1269-1277.

21 Gomez-Ospina N, Tsuruta F, Barreto-Chang O, Hu L, Dolmetsch $\mathrm{R}$. The C-terminus of the L-type voltage-gated calcium channel $\mathrm{Ca}_{(\mathrm{V})} 1.2$ encodes a transcription factor. Cell 2006; 127: 591-606.

22 Zhang W, Hirschler-Laszkiewicz I, Tong Q, Conrad K, Sun S-C, Penn L et al. TRPM2 is an ion channel that modulates hematopoietic cell death through activation of caspases and PARP cleavage. Am J Physiol Cell Physiol 2005; 290: 1146-1159.

23 Tsavaler L, Shapero MH, Morkowski S, Laus R. Trp-p8, a novel prostate-specific gene, is up-regulated in prostate cancer and other malignancies and shares high homology with transient receptor potential calcium channel proteins. Cancer Res 2001; 61: 3760-3769.

24 Zhang L, Barritt GJ. Evidence that TRPM8 is an androgendependent $\mathrm{Ca}^{2+}$ channel required for the survival of prostate cancer cells. Cancer Res 2004; 64: 8365-8373.

25 Thebault S, Lemonnier L, Bidaux G, Flourakis M, Bavencoffe A, Gordienko D et al. Novel role of cold/menthol-sensitive transient receptor potential melastatine family member 8 (TRPM8) in the activation of store-operated channels in LNCap Human prostate cancer epithelial cells. J Biol Chem 2005; 280: 39423-39435.

26 Monteith GR, McAndrew D, Faddy HM, Roberts-Thomson SJ. Calcium and cancer: targeting $\mathrm{Ca}^{2+}$ transport. Nature Rev 2007; 7: 519-530.

27 Maeda N, Niinobe M, Mikoshiba K. A cerebellar Pukinje cell marker P400 protein is an inositol 1,4,5-trisphosphate ( $\mathrm{InsP}_{3}$ ) receptor protein. Purificaation and characterization of $\mathrm{InsP}_{3}$ receptor complex. EMBO J 1990; 9: 61-67.

28 Malviya AN, Rogue P, Vincendon G. Sterospecific inositol 1,4,5[32] trisphosphate binding to isolated rat liver nuclei: evidence for inositol trisphosphate receptor-mediated calcium release form the nucleus. Proc Natl Acad Sci USA 1990; 87: 9270-9274.

29 Matter N, Ritz MF, Freyermuth S, Rogue P, Malviya AN. Stimulation of nuclear protein kinase $C$ leads to phosphorylation of nuclear inositol 1,4,5 trisphosphate receptor and accelerated calcium releases by inositol 1,4,5-trisphosphate form isolated rat liver nuclei. J Biol Chem 1993; 268: 732-736.

30 MacDonald JR. Nuclear calcium: transfer to and from the cytosol. Biol Signals Recept 1998; 7: 137-147.

31 Gerasimenko OK, Gerasimenko JV, Tepikin AV, Petersen OH. ATP-dependent accumulation and inositol trsphosphate- or cyclic ADP-ribose-mediated release of $\mathrm{Ca}^{2+}$ from the nuclear envelope. Cell 1995; 80: 439-444.

32 Boulay G, Brown DM, Qin N, Jiang M, Dietrich A, Zhu MX et al. Modulation of $\mathrm{Ca}^{(2+)}$ entry by polypeptides of the inositol 1,4,5trisphosphate receptor $\left(\mathrm{IP}_{3} \mathrm{R}\right)$ that bind transient receptor potential (TRP): evidence for roles of TRP and $\mathrm{IP}_{3} \mathrm{R}$ in store depletionactivated $\mathrm{Ca}^{(2+)}$ entry. Proc Natl Acad Sci USA 1999; 96: 14955-14960.

33 Zhu MX, Tang J. TRPC channel interactions with calmodulin and $\mathrm{IP}_{3}$ receptors. Novartis Found Symp 2004; 258: 44-58.

34 Nagamine K, Kudoh J, Minoshima S, Kawasaki K, Asakawa S, Ito $\mathrm{F}$ et al. Molecular cloning of a novel putative $\mathrm{Ca}^{2+}$ channel protein (TRPC7) highly expressed in brain. Genomics 1998; 54: 124-131.

35 Fonfria E, Marshall IC, Benham CD, Boyfield I, Brown JD, Hill K et al. TRPM2 channel opening in response to oxidative stress is dependent on activation of poly(ADP-ribose) polymerase. $\mathrm{Br} \mathrm{J}$ Pharmacol 2004; 143: 186-192. 